FOLIA POMERANAE UNIVERSITATIS TECHNOLOGIAE STETINENSIS

Folia Pomer. Univ. Technol. Stetin., Oeconomica 2017, 337(88)3, 5-12

\title{
ZASTOSOWANIE KLASYCZNEGO ALGORYTMU GENETYCZNEGO DO ROZWIAZYWANIA DYNAMICZNYCH MODELI PRODUKCJI
}

\author{
THE USAGE OF CLASSICAL GENETIC ALGORITHM FOR SOLVING DYNAMIC \\ PRODUCTION MODELS
}

Katedra Zastosowań Matematyki w Ekonomii, Zachodniopomorski Uniwersytet Technologiczny w Szczecinie, ul. Klemensa Janickiego 31, 71-270 Szczecin, e-mail: Anna.Landowska@zut.edu.pl

\begin{abstract}
Summary. The article presents the use of classical genetic algorithm for solving the dynamic models of plants production. The genetic algorithm was used to find the optimal value of three dynamic models: the serial, serial-to-parallel and parallel. The dynamic models concern four years of production and have been built to keep the conditions of crop rotation. Plants rotation is necessary to keep the soil in good condition and to obtain higher crops. On the basis of experiments the model and the method of selection and crossover used in the genetic algorithm was chosen. Chosen model and methods generate the best solution.
\end{abstract}

Słowa kluczowe: klasyczny algorytm genetyczny, model produkcji roślinnej, optymalizacja dynamiczna.

Key words: classical genetic algorithm, model of plants production, dynamic optimization.

\section{WSTĘP}

Artykuł przedstawia zastosowanie klasycznego algorytmu genetycznego do optymalizacji dynamicznej czteroletnich modeli produkcji roślinnej. Wcześniej tę metodę stosowano w pracy Landowskiej (2009) do problemu optymalnego przydziału oraz rozwiązując liniowy model produkcji roślinnej w okresie dwuletnim (Landowska 2011). Model produkcji został stworzony tak, aby zachodził w nim proces zmianowania roślin. Spełnienie warunków zmianowania roślin jest istotne dla utrzymania dobrej kultury gleby, co wiąże się z otrzymywaniem wyższego plonu. Niestosowanie zmianowania roślin powoduje wyjaławianie się gleby i skutkuje niższym plonem oraz rozprzestrzenianiem się chorób roślin. Optymalizacją modeli produkcji roślinnej zajmowali się między innymi Więckowski (1982) i Zaród $(2004,2008)$.

Celem artykułu jest zastosowanie heurystycznej metody klasycznego algorytmu genetycznego (AG) do planowania produkcji roślinnej oraz dobranie w sposób eksperymentalny odpowiedniej metody selekcji i krzyżowania w AG do dynamicznego modelu optymalizacyjnego. Eksperymenty przeprowadzono na modelach zbudowanych na podstawie danych statystycznych Głównego Urzędu Statystycznego obejmujących lata 2007-2010. Istotą klasycznego algorytmu genetycznego jest przeszukiwanie w sposób losowy przestrzeni rozwiązań w celu znalezienia w kolejnych iteracjach rozwiązania o wartości większej niż wygenerowane w poprzednich etapach. Metodą tą rozwiązano modele etapowe przedstawiające plany produkcji roślinnej. 
Modele etapowe: szeregowy, szeregowo-równoległy i równoległy różnią się konstrukcją i liczbą etapów optymalizacji. W modelu równoległym wszystkie lata produkcji są optymalizowane równocześnie, natomiast $w$ pozostałych modelach optymalizacja kolejnych lat następuje oddzielnie przy uwzględnieniu wyników z poprzednich okresów produkcji. Podejście takie daje możliwość optymalizacji planu produkcji również w przypadkach, gdy dane są wyniki z poprzednich okresów produkcji, i uwzględnienia ich w planowaniu.

\section{KONCEPCJA I SCHEMATY PLANOWANIA LINIOWO-DYNAMICZNEGO}

W artykule optymalizacji podlegały 3 liniowo-dynamiczne modele produkcji: szeregowy, szeregowo-równoległy i równoległy. Konstrukcja modeli została opisana w pracy Landowskiej i Landowskiego (2012), w której dla przykładu za pomocą metody simpleks rozwiązano modele obejmujące lata 2005-2008. Różnica pomiędzy modelami (szeregowym, szeregowo-równoległym i równoległym) dotyczy liczby etapów optymalizacji. Każdy z modeli obejmuje 4 kolejne okresy produkcji. Dynamiczna postać modeli polega na tym, że zostały one stworzone tak, iż optymalizacja kolejnych okresów produkcji opiera się na rozwiązaniu otrzymanym w poprzednim okresie, zgodnie z zasadą optymalności Bellmana (1957). Kolejne okresy produkcji są ze sobą powiązane warunkami ograniczającymi.

Model szeregowy

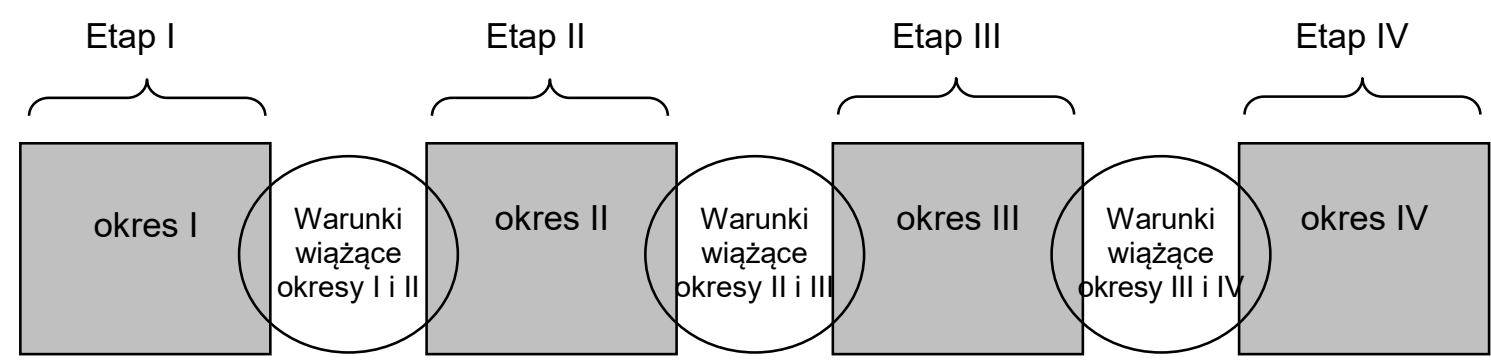

Model szeregowo-równoległy

Etap I

Etap II

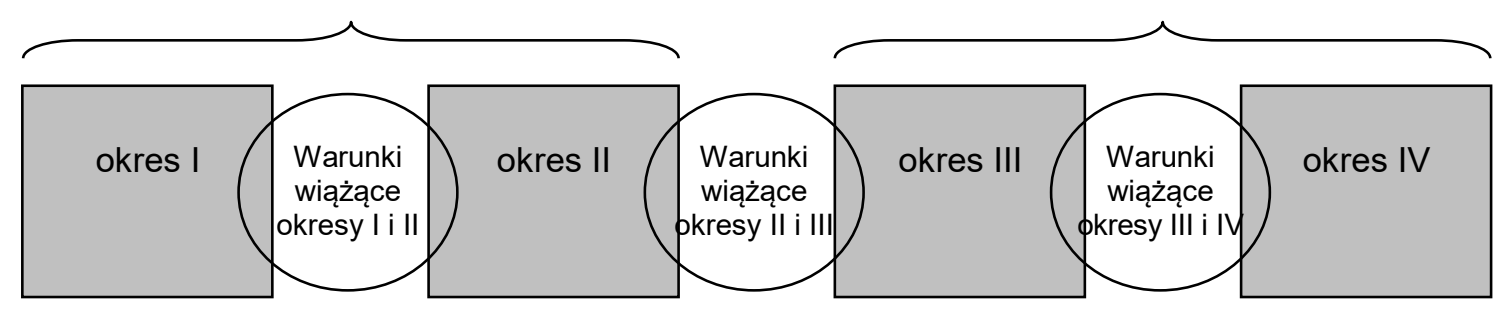

Model równoległy

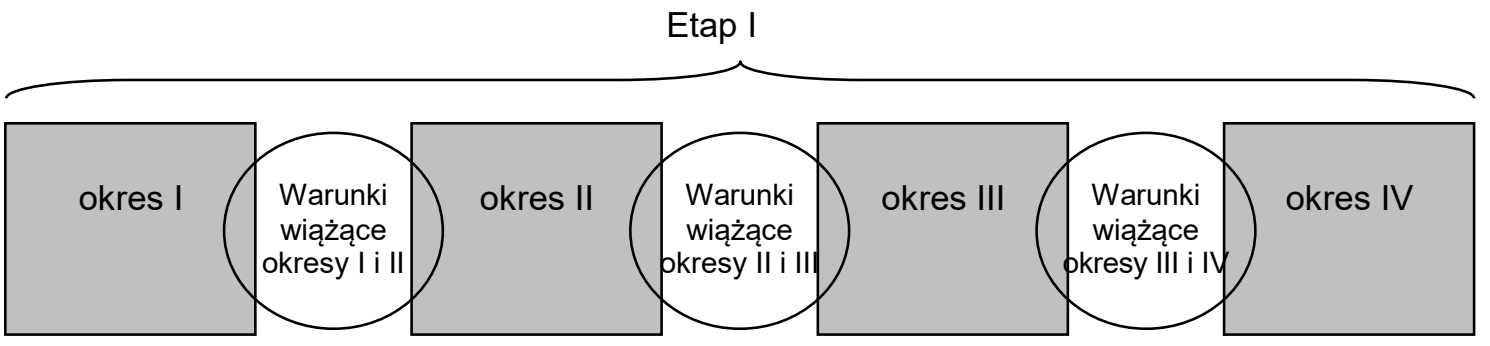

Ryc. 1. Etapowe modele dynamiczne szeregowy, szeregowo-równoległy i równoległy 
Model równoległy jest jednoetapowym modelem dynamicznym, co oznacza, że wszystkie okresy produkcji są optymalizowane jednocześnie w jednym etapie. Model szeregowo-równoległy jest dwuetapowy. Okres czteroletni został podzielony na 2 części - pierwsza część obejmuje pierwszy i drugi rok produkcji, natomiast druga część - trzeci i czwarty okres produkcji. Pierwsza i druga część są ze sobą powiązane warunkami ograniczającymi, tak aby spełnione były warunki zmianowania roślin w całym okresie produkcji. Optymalizacja modelu szeregowo-równoległego następuje w dwóch etapach - najpierw podlega optymalizacji pierwsza część modelu, następnie na podstawie otrzymanych wyników optymalizowana jest druga część modelu. Model szeregowy jest dynamicznym modelem czteroetapowym. Każda z 4 części modelu jest optymalizowana szeregowo - jedna po drugiej. Wyniki po każdym etapie optymalizacji są uwzględniane w kolejnym kroku optymalizacji. Na rycinie 1 przedstawiono schematy optymalizacji modeli dynamicznych: szeregowego, szeregowo-równoległego i równoległego (Landowska i Landowski 2012).

\section{KLASYCZNY ALGORYTM GENETYCZNY}

Algorytmy ewolucyjne, do których należy klasyczny algorytm genetyczny, zostały stworzone tak aby naśladowały naturę. Osobniki pewnej populacji mają różny materiał genetyczny; w procesie rozmnażania się poprzez krzyżowanie materiału genetycznego rodziców i jego mutację powstaje materiał genetyczny potomków. Klasyczny algorytm genetyczny jest metodą heurystyczną, która poszukuje rozwiązania poprzez modyfikację wyselekcjonowanych wyników z otrzymanej wcześniej populacji rozwiązań. Następuje krzyżowanie 2 wyników z poprzedniej iteracji oraz mutacja otrzymanych rozwiązań. Mutacja w przyrodzie występuje bardzo rzadko, zatem w algorytmie genetycznym prawdopodobieństwo wykonania operacji mutacji będzie bardzo małe. W każdej iteracji wybierane jest rozwiązanie, które jest najlepiej dopasowane do warunków zadanych; wartość ta zostanie przyjęta jako wartość optymalna z danej iteracji.

Załóżmy, że każdy osobnik w generacji będzie składał się z ciągu binarnego i że na poszczególnych bitach będą dokonywane operacje, prowadzące do znalezienia wartości optymalnej.

Kolejne etapy klasycznego algorytmu genetycznego szczegółowo opisują w swoich pracach Bobenhofer (2001) i Rutkowski (2005). Kroki AG przedstawiono na ryc. 2.

Jak wspomniano wyżej, operacja krzyżowania występuje w przyrodzie bardzo często. Zatem przyjmuje się, że krzyżowanie będzie wykonywane z prawdopodobieństwem z przedziału $[0,5 ; 1]$, natomiast mutacja wśród osobników żyjących w środowisku naturalnym jest mało spotykana. Zatem w AG mutacja elementów będzie się odbywała z prawdopodobieństwem z przedziału [0; 0,1] - Rutkowski (2005).

W rozpatrywanym modelu produkcji roślinnej osobnikami populacji są poszczególne rozwiązania produkcji (plany zasiewów) zapisane w postaci ciągów binarnych, w których jest możliwa zmiana rozwiązania poprzez korektę w poszczególnych bitach ciągu binarnego.

Etap selekcji klasycznego algorytmu genetycznego służy wytypowaniu osobników, które są najlepiej dostosowane, czyli tych ciągów bitów, które dają najlepszą wartość funkcji dopasowania; w przypadku minimalizacji najmniejszą, a przy maksymalizacji największą wartość funkcji celu. Selekcja osobników może odbywać się w sposób deterministyczny albo w sposób losowy. 


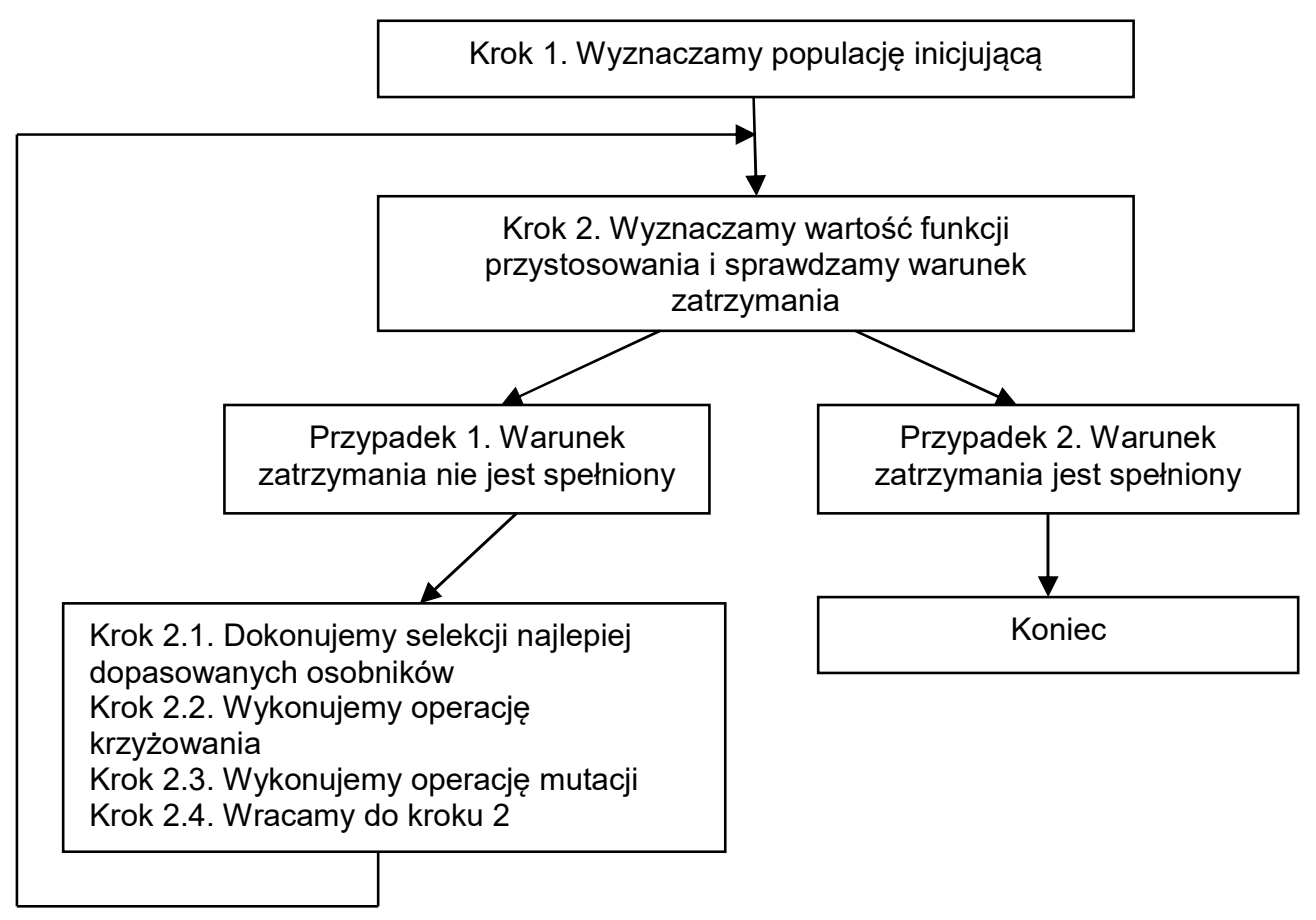

Ryc. 2. Schemat klasycznego algorytmu genetycznego Źródło: opracowano na podstawie: Rutkowski (2005).

Przy wyborze losowym największe prawdopodobieństwo wyselekcjonowania przypisuje się osobnikom z największą wartością funkcji przystosowania (przy maksymalizacji). Najczęściej stosowane metody selekcji to metoda ruletki lub metoda turniejowa. W metodzie ruletki osobnik, który przechodzi do następnej generacji, wybierany jest na podstawie przypisanej wartości prawdopodobieństwa. Największe prawdopodobieństwo otrzymują rozwiązania najlepiej przystosowane, przy maksymalizacji są to rozwiązania z największą wartością funkcji celu. W metodzie selekcji turniejowej wybierane są pary rozwiązań. Te pary, które są najlepiej przystosowane, tworzą potomków; w taki sposób tworzona jest nowa generacja rozwiązań. Metody selekcji szczegółowo opisuje Rutkowski (2005).

Krzyżowania osobników w generacji dokonuje się w celu wymiany informacji pomiędzy otrzymanymi rozwiązaniami. Krzyżowanie polega na zamianie poszczególnych bitów dla danych osobników w generacji. W wyniku tej operacji powstaje nowa generacja generująca nowy zestaw rozwiązań. Metody krzyżowania to między innymi: metoda jednopunktowa, metoda dwupunktowa, metoda rozproszona (Rutkowski 2005). Metody te różnią się liczbą wskazanych bitów, od których dokonywane są zamiany. Na przykład metoda jednopunktowa wskazuje jeden bit, od którego zaczyna się zamiana. W metodzie dwupunktowej wybierane są 2 bity - pierwszy wskazuje początek zamiany, a drugi - jej koniec. Krzyżowanie metodą rozproszoną polega na wylosowaniu wektora o wartościach binarnych długości takiej jak rozwiązania. W miejscach, w których wartość losowego wektora wynosi 1, następuje zamiana bitów w krzyżowanych osobnikach.

Kolejnym etapem jest mutacja. Operacja ta wykonywana jest na poszczególnych bitach osobników nowej generacji. Dla każdego bita losowane jest prawdopodobieństwo i jeżeli wylosowana wartość jest mniejsza od założonej wartości prawdopodobieństwa mutacji, to dokonywana jest zmiana bita na bit przeciwny. Mutacja, jak już wspomniano, następuje bardzo rzadko. 


\section{WYNIKI}

W wyjściowym modelu równoległym produkcji roślinnej jako funkcję celu przyjęto wartość dochodu rolniczego, wyrażonego w tysiącach PLN. Optymalizacja modelu dotyczy maksymalizacji funkcji celu (dochodu rolniczego). Warunki ograniczające modelu to nierówności, które gwarantują prawidłowe zmianowanie roślin w poszczególnych latach produkcji, zapewniają również procentowy udział zbóż w całym planie produkcji oraz wprowadzają ograniczenia dotyczące zasiewu roślin okopowych. W planie produkcji rozpatrywanego modelu uwzględniano zasiew: pszenicy, żyta, jęczmienia, owsa, pszenżyta i rzepaku oraz sadzenie ziemniaków i buraków. Dokonując dekompozycji modelu równoległego, otrzymano model szeregowo-równoległy i szeregowy.

$\mathrm{Na}$ podstawie modeli szeregowego, szeregowo-równoległego i równoległego wykonano łącznie 5400 eksperymentów - po 1800 eksperymentów dla każdego modelu. Otrzymano wyniki uzależnione od metody selekcji i krzyżowania. W eksperymentach stosowano metody selekcji turniejowej i ruletkę oraz metody krzyżowania: rozproszoną, jednopunktową i dwupunktową.

W następnych rozważaniach oznaczenia, dotyczące jednego z 6 przypadków, będą obejmowały dobór odpowiedniej metody selekcji i krzyżowania w AG. Odpowiednio przypadek 1 oznacza selekcję turniejową, krzyżowanie metodą rozproszoną; przypadek 2 - selekcję turniejową, krzyżowanie metodą jednopunktową; przypadek 3 - selekcję turniejową, krzyżowanie metodą dwupunktową; przypadek 4 - selekcję metodą ruletki, krzyżowanie metodą rozproszoną; przypadek 5 - selekcję metodą ruletki, krzyżowanie metodą jednopunktową; przypadek 6 selekcję metodą ruletki, krzyżowanie metodą dwupunktową.

W tabeli 1 przedstawiono maksymalne wartości funkcji celu, będącej wartością dochodu rolniczego, otrzymane na podstawie eksperymentów wykonanych dla 3 modeli oraz różnych metod selekcji i krzyżowania w algorytmie genetycznym.

Tabela 1. Wartość funkcji celu (dochodu rolniczego) dla 6 kombinacji metod selekcji i krzyżowania wykorzystanych w AG do optymalizacji modeli szeregowego, szeregowo-równoległego i równoległego

\begin{tabular}{|l|c|c|c|c|c|c|}
\hline \multirow{2}{*}{$\begin{array}{c}\text { Dochód } \\
\text { rolniczy }\end{array}$} & \multicolumn{5}{|c|}{ Rodzaj metody selekcji (S) i krzyżowania (K) w AG } \\
\cline { 2 - 7 } & $\begin{array}{c}\text { przypadek 1 } \\
\text { S: turniej } \\
\text { K: rozproszone }\end{array}$ & $\begin{array}{c}\text { przypadek 2 } \\
\text { S: turniej } \\
\text { K: jednopunktowe }\end{array}$ & $\begin{array}{c}\text { przypadek 3 } \\
\text { S: turniej } \\
\text { K: dwupunktowe }\end{array}$ & $\begin{array}{c}\text { przypadek 4 } \\
\text { S: ruletka } \\
\text { K: rozproszone }\end{array}$ & $\begin{array}{c}\text { przypadek 5 } \\
\text { S: ruletka } \\
\text { K: jednopunktowe }\end{array}$ & $\begin{array}{c}\text { przypadek } 6 \\
\text { S: ruletka } \\
\text { K: dwupunktowe }\end{array}$ \\
\hline $\begin{array}{l}\text { Dla modelu } \\
\text { szeregowego } \\
\text { [PLN] }\end{array}$ & 96228 & 96259 & 96206 & 96182 & 96398 & 96050 \\
\hline $\begin{array}{l}\text { Dla modelu } \\
\text { szeregowo- } \\
\text {-równoległego } \\
\text { [PLN] }\end{array}$ & 96199 & 95795 & 95636 & 95780 & 95914 & 95979 \\
\hline $\begin{array}{l}\text { Dla modelu } \\
\text { równoległego } \\
\text { [PLN] }\end{array}$ & 93824 & 93798 & 93996 & 93398 & 93795 & 93670 \\
\hline
\end{tabular}

Analizując otrzymane wyniki, widzimy, że największe wartości uzyskano dla modelu szeregowego, w którym dla każdego przypadku wartość funkcji celu jest największa. W każdym z 6 przypadków wartość dochodu rolniczego dla modelu szeregowego przekracza 96 tys. PLN, wartości maksymalne funkcji celu dla 6 przypadków dla modelu szeregowo-równoległego zawierają się w przedziale od 95636 PLN do 96199 PLN. Najmniejsze 
wartości funkcji celu otrzymano dla modelu równoległego; przyjmują one wartości poniżej 94 tys. PLN. Największa wartość dochodu rolniczego, jaką otrzymano z eksperymentów metodą AG, wynosi 96398 PLN. Wartość tę wygenerowano dla modelu szeregowego (przypadek 5: selekcja metodą ruletki, krzyżowanie metodą jednopunktową).

W tabeli 2 przedstawiono wartości średniej arytmetycznej oraz klasycznego współczynnika zmienności, otrzymane dla dochodów rolniczych wygenerowanych metodą algorytmu genetycznego. Największą wartość średnią funkcji celu otrzymano dla modelu szeregowego (przypadek 5: selekcja metodą ruletki, krzyżowanie metodą jednopunktową); średnia ta wynosi 93664 PLN. Dla 3 modeli dynamicznych produkcji największą wartość średniej w każdym z 6 przypadków doboru metody selekcji i krzyżowania otrzymano dla modelu szeregowego, najmniejszą - dla modelu równoległego.

Tabela 2. Średnie arytmetyczne oraz wartości klasycznego współczynnika zmienności otrzymanych dochodów rolniczych (funkcji celu) dla poszczególnych przypadków selekcji (S) i krzyżowania (K) oraz różnych modeli optymalizacyjnych

\begin{tabular}{|l|c|c|c|c|c|c|}
\hline \multirow{2}{*}{ Model } & $\begin{array}{c}\text { Przypadek 1 } \\
\text { S: turniej } \\
\text { K: rozproszone }\end{array}$ & \begin{tabular}{c} 
Przypadek 2 \\
S: turniej \\
\cline { 2 - 7 }
\end{tabular} & $\begin{array}{c}\text { Przypadek 3 jednopunktowe } \\
\text { S: turniej } \\
\text { K: dwupunktowe }\end{array}$ & $\begin{array}{c}\text { Przypadek 4 } \\
\text { S: ruletka } \\
\text { K: rozproszone }\end{array}$ & $\begin{array}{c}\text { Przypadek 5 } \\
\text { S: ruletka } \\
\text { K: jednopunktowe }\end{array}$ & $\begin{array}{c}\text { Przypadek 6 } \\
\text { S: ruletka } \\
\text { K: dwupunktowe }\end{array}$ \\
\hline Szeregowy & 93584 & 93633 & 93558 & 93605 & 93664 & 93526 \\
\hline $\begin{array}{l}\text { Szeregowo- } \\
\text {-równoległy }\end{array}$ & 93103 & 93180 & 93041 & 93062 & 93252 & 93222 \\
\hline Równoległy & 90573 & 90576 & 90487 & 90586 & 90503 & 90576 \\
\hline \multicolumn{7}{|c|}{ Klasyczny współczynnik zmienności [\%] } \\
\hline Szeregowy & 1,23 & 1,20 & 1,20 & 1,10 & 1,19 & 1,19 \\
\hline $\begin{array}{l}\text { Szeregowo- } \\
\text {-równoległy }\end{array}$ & 1,18 & 1,22 & 1,18 & 1,27 & 1,14 & 1,06 \\
\hline Równoległy & 1,07 & 1,16 & 1,14 & 1,14 & 1,19 & 1,06 \\
\hline
\end{tabular}

Wartość klasycznego współczynnika zmienności w przypadkach 1-4 najmniejsza jest dla modelu równoległego, w przypadku 5 - najmniejsza jest dla modelu szeregowo-równoległego, a w przypadku 6 wartości współczynnika zmienności dla modeli szeregowo-równoległego i równoległego są równe i wynoszą 1,06\%. Wartości współczynnika zmienności, jakie otrzymano na podstawie eksperymentów, nie są znacząco różne - maksymalna wartość wynosi $1,27 \%$ (model szeregowo-równoległy; przypadek 4), a minimalna - 1,06\% (modele szeregowo-równoległy i równoległy; przypadek 6), rozrzut jest zatem niewielki i wynosi 0,21 punktu procentowego.

$\mathrm{Na}$ podstawie przeprowadzonych badań można stwierdzić, że za pomocą metody klasycznego algorytmu genetycznego można wygenerować rozwiązanie modelu dynamicznego produkcji roślinnej, przy czym otrzymane wyniki są możliwe do przyjęcia. Należy pamiętać, że metoda ta jest metodą heurystyczną i że nie w każdym przypadku może doprowadzić do optymalnego rozwiązania.

Analizując średnią arytmetyczną i klasyczny współczynnik zmienności, można stwierdzić, że najlepsze wyniki dotyczyły modelu szeregowego. Dla tego modelu średnia arytmetyczna otrzymanego dochodu rolniczego jest największa, przy uwzględnieniu stosowanych metod 
selekcji i krzyżowania. W modelu szeregowym dla przypadku 5 (selekcja: ruletka, krzyżowanie: metoda jednopunktowa) otrzymano największą wartość funkcji celu wynoszącą 96398 PLN. Zatem można stwierdzić, że model szeregowy, w którym w AG wykorzystano selekcję metodą ruletki i krzyżowanie jednopunktowe, daje najlepsze wyniki w procesie optymalizacji.

W tabeli 3 przedstawiono plan zasiewu z największą wartością dochodu rolniczego (przypadek 5) dla modelu szeregowego.

Tabela 3. Struktura produkcji roślinnej otrzymana za pomocą modelu szeregowego optymalizacji dynamicznej (metoda AG; selekcja: ruletka; krzyżowanie: metoda jednopunktowa)

\begin{tabular}{|l|c|c|c|c|}
\hline \multicolumn{1}{|c|}{ Roślina } & Okres I & Okres II & Okres III & Okres IV \\
\hline Pszenica [ha] & 2,00 & 2,03 & 2,34 & 2,21 \\
\hline Jęczmień [ha] & 0,84 & 1,26 & 1,36 & 1,13 \\
\hline Żyto [ha] & 3,70 & 3,23 & 2,84 & 3,13 \\
\hline Owies [ha] & 1,45 & 1,96 & 1,63 & 1,17 \\
\hline Pszenżyto [ha] & 1,50 & 1,13 & 1,45 & 1,86 \\
\hline Rzepak [ha] & 1,84 & 1,71 & 1,84 & 1,84 \\
\hline Ziemniaki [ha] & 0,43 & 0,43 & 0,45 & 0,15 \\
\hline Buraki [ha] & 1,41 & 1,31 & 1,26 & 1,52 \\
\hline Inne uprawy [ha] & 0,00 & 0,11 & 0,00 & 0,16 \\
\hline Dochód rolniczy [PLN] & 27172 & 19897 & 25312 & 24017 \\
\hline Suma dochodu rolniczego [PLN] & \multicolumn{4}{|c|}{96398} \\
\hline
\end{tabular}

W otrzymanym planie produkcji dominującą rośliną w 4 kolejnych okresach jest żyto. Zasiew roślin, takich jak pszenica, jęczmień, owies, pszenżyto, rzepak i buraki, w poszczególnych okresach jest rozłożony równomiernie. Najmniejsze wartości zasiewu dotyczyły ziemniaków i innych upraw.

\section{PODSUMOWANIE}

W artykule przedstawiono zastosowanie klasycznego algorytmu genetycznego do optymalizacji 3 dynamicznych modeli produkcji roślinnej: szeregowego, szeregowo-równoległego i równoległego. Każdy z modeli dotyczył czteroletniego okresu produkcji (lat 2007-2010). Warunki wiążące kolejne lata produkcji, wykorzystane w modelach, powodują, że zachowano prawidłowe zmianowanie roślin, które jest niezbędne dla utrzymania gleby w dobrej kulturze i otrzymania wysokich plonów produkcji.

$\mathrm{Na}$ podstawie wyników eksperymentów wybrano model i metody wykorzystywane w AG do optymalizacji, które dały najlepsze wyniki. Największą wartość funkcji celu, mediany oraz średniej arytmetycznej otrzymano dla modelu szeregowego. Dla modelu szeregowego największa wartość dochodu rolniczego (funkcja celu) wynosi 96398 PLN, wynik taki otrzymano dla algorytmu genetycznego, gdzie wykorzystano metodę selekcji ruletka i metodę krzyżowania jednopunktową.

Wykorzystanie metody AG do optymalizacji produkcji wykazało, że możliwe jest użycie metody klasycznego algorytmu genetycznego do optymalizacji modelu dynamicznego z czteroletnim okresem produkcji, przy zachowaniu wszystkich zależności wiążących poszczególne okresy produkcji. 
Zaletą metody AG jest jej uniwersalność, może ona rozwiązywać zadania liniowe i nieliniowe, statyczne i dynamiczne, jak również modele z parametrami losowymi. Najczęściej stosowana klasyczna metoda programowania liniowego (metoda simplex) wymaga, na przykład spełnienia założenia liniowości warunków ograniczających, co znacznie ogranicza możliwości konstrukcyjne modeli decyzyjnych.

\section{PIŚMIENNICTWO}

Bellman R.E. 1957. Dynamic programming. Princeton University Press, NJ. ISBN 0-486-42809-5.

Bobenhofer U. 2001. Genetic algorithms: Theory and applications, 2nd ed., Linz, Austria, Johannes Kepler Univ.

Landowska A. 2009. Rozwiązanie problemu optymalnego przydziału za pomocą klasycznego algorytmu genetycznego. Folia Pomer. Univ. Technol. Stetin., Oeconomica 275(57), 53-58.

Landowska A. 2011. Klasyczny algorytm genetyczny w dynamicznej optymalizacji modelu liniowego produkcji roślinnej. Folia Pomer. Univ. Technol. Stetin., Oeconomica 285(62), 45-50.

Landowska A., Landowski M. 2012. Zastosowanie wybranych modeli optymalizacji dynamicznej struktury produkcji roślinnej w przeciętnym gospodarstwie rolnym. Folia Pomer. Univ. Technol. Stetin, Oeconomica 297(68), 47-54.

Rutkowski L. 2005. Metody i techniki sztucznej inteligencji. Warszawa, PWN.

Więckowski W. 1982. Optymalizacja plonu produkcji przedsiębiorstwa rolnego przy użyciu rozwiązań standardowych. Warszawa, PWN.

Zaród J. 2004. Rozwiązania prymalne i dualne liniowych modeli gospodarstw rolnych województwa zachodniopomorskiego. Metody i zastosowania badań operacyjnych '04. Red. T. Trzaskalik, Katowice, AE, 405-415.

Zaród J. 2008. Programowanie liniowo-dynamiczne jako narzędzie analizujące zmiany w funkcjonowaniu gospodarstw rolnych. Łódź, Wydaw. UŁ, 429-435.

Streszczenie. Artykuł przedstawia zastosowanie klasycznego algorytmu genetycznego do rozwiązywania modeli dynamicznych produkcji roślinnej. Algorytm genetyczny wykorzystano do znajdowania wartości optymalnej trzech modeli dynamicznych: szeregowego, szeregowo-równoległego i równoległego. Modele dynamiczne obejmują czteroletni okres produkcji; zostały zbudowane tak, aby zachować warunki płodozmianu. Zmianowanie roślin jest konieczne dla utrzymania gleby $w$ dobrej kulturze i uzyskania wyższych plonów. Na podstawie eksperymentów wybrano model oraz metodę selekcji i krzyżowania, wykorzystaną w algorytmie genetycznym, które generują najlepsze rozwiązanie. 